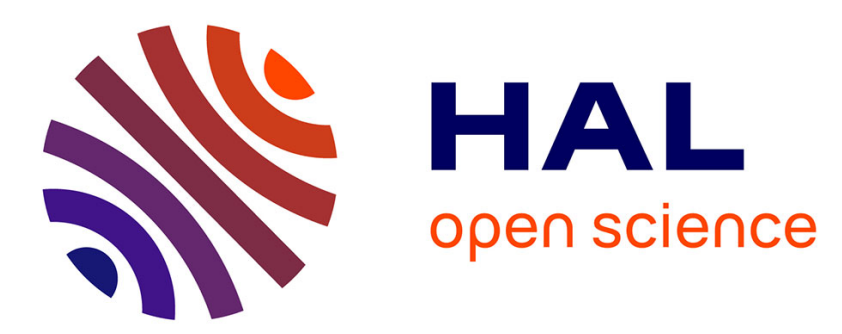

\title{
A water-based process for the surface functionalisation of ceramic fibres
}

Lucile Henry, Nicolas Biscay, Chrystel Huguet, Sylvie Loison, Cyril Aymonier

\section{To cite this version:}

Lucile Henry, Nicolas Biscay, Chrystel Huguet, Sylvie Loison, Cyril Aymonier. A water-based process for the surface functionalisation of ceramic fibres. Green Chemistry, 2020, 22 (23), pp.8308-8315. 10.1039/D0GC02987D . hal-03048162

\section{HAL Id: hal-03048162 https://hal.science/hal-03048162}

Submitted on 16 Dec 2020

HAL is a multi-disciplinary open access archive for the deposit and dissemination of scientific research documents, whether they are published or not. The documents may come from teaching and research institutions in France or abroad, or from public or private research centers.
L'archive ouverte pluridisciplinaire HAL, est destinée au dépôt et à la diffusion de documents scientifiques de niveau recherche, publiés ou non, émanant des établissements d'enseignement et de recherche français ou étrangers, des laboratoires publics ou privés. 
Received 00th January 20xx, Accepted 00th January 20xx DOI: $10.1039 / \times 0 \times x 00000 x$

\title{
A water-based process for the surface functionalisation of ceramic fibres
}

\author{
L. Henry, ${ }^{a}$ N. Biscay, ${ }^{a}$ C. Huguet, ${ }^{b}$ S. Loison, ${ }^{b}$ and C. Aymonier ${ }^{a^{*}}$
}

\begin{abstract}
This research work applied the hydrothermal process to the surface treatment of ceramic fibres which are integrated into the fabrication of ceramic matrix composites (CMCs). In the conventional process, the main step consists in dissolving the oxidised phases at the fibre surface using strong acids. As a consequence, the chemical homogeneity of the surface is improved and a microporous carbon (C) film is generated at the fibre surface. The C-rich surface enhances the compatibility of the fibre with the pyrocarbon interphase that is deposited on the fibres prior matrix deposition when processing CMCs. This paper shows the possibility to substitute this conventional process using strong acids by a hydrothermal treatment. Indeed, as water displays tunable physico-chemical properties as a function of temperature and pressure, it is possible to recover fibres demonstrating similar surface characteristics as the ones obtained after the reference acid-based treatment. The efficiency of the hydrothermal treatment is assessed through optimised surface properties obtained after one single step process operating in a semi-continuous mode. Then, the mechanism investigation reveals a selective attack of the $\mathrm{Si}$ atoms contained in the fibre via a hydrolysis reaction. Besides, it is denoted that the process follows a zero order kinetics. This allows a fine control of the fiber surface properties to obtain CMC with high

thermomechanical

performance.
\end{abstract}

\section{Introduction}

The global air traffic undergoes a constant growth as the passenger number increased from few millions in 1950 to 4.3 billion in 2018. ${ }^{1}$ In that context, the Advisory Council for Aviation Research and Innovation in Europe (ACARE) developed a Strategic Research Agenda (SRA) aimed at meeting the goals of Vision 2050. The Vision 2050 program has been built to face global warming effects. The objectives are to decrease the NOx and $\mathrm{CO}_{2}$ emissions by $90 \%$ and $75 \%$, respectively, and to lower the noise pollution by $65 \%$.

To achieve the Vision 2050 objectives, both the decrease of the total weight of planes and the enhancement of the motor performance are solutions to load and consume less fuel. Ceramic Matrix Composites (CMC) can address those two challenges by replacing the commonly-used superalloys and consequently reducing the weight and allowing new design for aircraft engines parts. They demonstrated similar mechanical properties for a $50 \%$ weight reduction ${ }^{2}$ and have already been used in recent aircraft engines. ${ }^{3}$ Due to a high-volume fibre fraction, CMCs are highly resistant to fatigue at long period of times and high temperatures. ${ }^{4,5}$ Besides, they display a high resistance to chemicals and thermal shock. To conclude, CMCs are excellent candidates to be used as constructive parts in high temperature areas in aircrafts as they show high thermomechanical properties under extreme conditions (oxidizing, corrosive or reducing atmospheres). Especially, silicon carbide-based CMCs are already used for hightechnology applications as they lead to the highest performances. ${ }^{6}$

During its fabrication, physico-chemical phenomena take place at the fibre-matrix interface. In fact, chemical, tribological and tribochemical reactions occur at high temperature leading to a dramatic drop of the CMCs performance. Moreover, adhesion phenomena exist between the fibre and the matrix. Indeed, the efficiency of both the transfer load from the matrix to the fibre and the fibre pull-out are dependent of these phenomena. That is the reason why CMCs adopt a mechanical behaviour either fragile or pseudo-ductile when submitted to stress. Hence, the surface treatment of the fibres prior to the fabrication process of the composites needs to be precisely controlled to optimise the physico-chemical properties of the interface and, in fine, the thermomechanical properties of the CMCs.

\footnotetext{
a. CNRS, Univ. Bordeaux, Bordeaux INP, ICMCB, UMR 5026, 33600 Pessac, France. Email: cyril.aymonier@icmcb.cnrs.fr.

${ }^{b .}$ Safran Ceramics, Les cinq chemins - rue de Touban, 33185 Le Haillan, France.

† Footnotes relating to the title and/or authors should appear here.

Electronic Supplementary Information (ESI) available: [details of any supplementary information available should be included here]. See DOI: $10.1039 / x 0 x \times 00000 x$
} 
This paper describes the hydrothermal treatment of ceramic fibres as an alternative to the conventional acid-based method. These fibres are made of small crystalline SiC particles (1-3 nm) embedded in an amorphous phase. According to Laffon et al., the crystalline phase accounts for 55 wt.\% of the total weight, the amorphous phase (oxycarbidic silicon $\mathrm{SiC}_{\mathrm{x}} \mathrm{O}_{\mathrm{y}}$ phase) for $40 \mathrm{wt} . \%$ and the free carbon organised in Basic Structural Units for 5 wt.\%. ${ }^{7}$ At their surface, an oxygen-rich layer forms when exposed to air. Although this external layer could be assimilated to a C-rich silica layer ${ }^{8}$, XPS measurement revealed the presence of a pure silica layer on the top of a desized Nicalon NL 200 fibres. $^{9}$ As this oxide layer is rigid, the mechanical properties of the CMCs are diminished. Hence, the deposition of one or more less rigid layers between the matrix and the fibres (interphase) leads to an increase of the composite toughness. ${ }^{10}$ The damage tolerance of CMCs can be enhanced by using pyrocarbon and boron nitride as interphases. ${ }^{11}$ Indeed, their layered structure results in a weak fibre-matrix interface which develops low adhesion strength. Consequently, the interphase can deflect the matrix cracks by causing the debonding of the fibres. ${ }^{12}$ Crack growth is then limited, and the composite failure is delayed. In the case of pyrocarbon interphases the fibre surface needs to be homogeneous and chemically compatible, in order to promote the anchorage of the interphase. An industrial method to dissolve the oxide layer and to grow a C-rich interface at the surface of the Nicalon fibres up to a thickness of $100 \mathrm{~nm}$ was patented. The 3 step-treatment is the following: i) the fibres are desized under air at high temperatures $\left(400-600{ }^{\circ} \mathrm{C}\right)$, then ii) they are soaked into a mixture of nitric, acetic and fluorhydric acid, and iii) they are rinsed out with water. ${ }^{13}$ After the acidic treatment, the oxide layer thickness is reduced to 5 $\mathrm{nm}$ and the fibres are covered with a microporous $\mathrm{C}$ film. However, this acidic treatment is extremely harmful for the environment as large quantity of strong acids and water are used. The treatment requires various equipment at each step generating additional costs and time.

Our recent research work demonstrated the possibility to solubilise silicon (Si) atoms from the fibre surface and to generate a $\mathrm{C}$ film with only water under high pressure and temperature. ${ }^{14}$ Moreover, carbon nanomaterials have already been prepared by this type of method. ${ }^{15,16}$

Hence, this paper clarifies the utilisation of water instead of strong acids to modify the surface of SiC fibres. The optimisation of the surface properties of the treated fibres is achieved by tailoring the interaction between water and the Si atoms. Practically, the behaviour of subcritical water is investigated with the variation of experimental conditions as temperature, pressure, time and nature of the solvent.

\section{Experimental sections}

\subsection{Materials}

SiC ceramic fibres were provided by the Safran Ceramics company. The NL 200 Nicalon fibres are manufactured by NGS Advanced Fibers Co. The tow is composed of $12 \mu \mathrm{m}$ diameter filaments and shows a linear density of 210 tex. Distilled water and ethanol (pure at $95 \%$ and bought from Sigma Aldrich) were used as reactants. Ethanol enables to remove the sizing of the raw tow which consists in polyvinyl alcohol (PVA) without modifying the surface properties of the fibres. This sample is referred as desized fibres.

\subsection{Reactor}

The experiments were performed in a tubular reactor of $62 \mathrm{~cm}$ length with a capacity of $3.3 \mathrm{~mL}$. The whole set-up (Fig.1) is

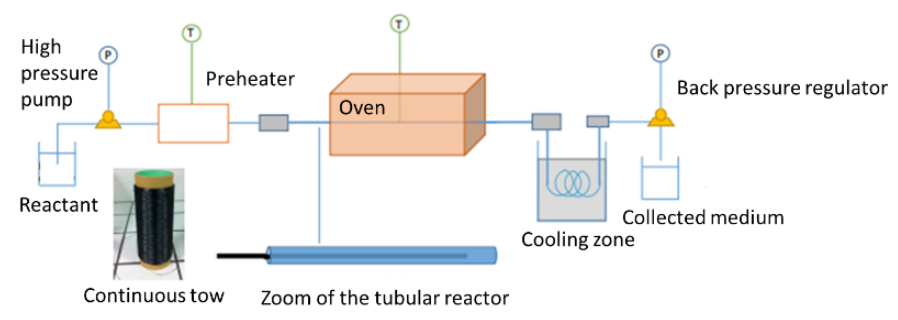

made of a Jasco PU 2080 Plus high-pressure pump, a preheating system and a cooling zone followed by a Jasco BP 2080 Plus back pressure regulator in order to operate in a semi-continuous mode. A $62 \mathrm{~cm}$ long tow is placed inside the tubular reactor which settles in the oven already at the process temperature. When the reactor is sealed, the reactive medium is injected in the circuit and the temperature of the preheater is set at the same process temperature. Then, the pressure is fixed (between the saturated vapour and $30 \mathrm{MPa}$ ) and the treatment is run during a determined time period (less than $2 \mathrm{~h}$ ). At the end of the treatment preiod, the set-up is depressurised, and the heating systems and the injection pump are turned off. The reactor can be open to retrieve the dried and treated tow. The material is directly characterised.

Fig.1 Scheme of the experimental set-up used to treat SiC ceramic fibres.

\subsection{Characterisation techniques}

The surface of all the fibres was analysed by Auger Electron Spectroscopy (AES 310F from Thermofischer Scientific) and XRay Photoelectron Spectroscopy (XPS K-Alpha from Thermofischer Scientific). AES was performed with an acceleration voltage of $10 \mathrm{kV}$. The etching was performed with an Argon beam of $4.5 \mathrm{keV}$ and the etching spot diameter was about $50 \mathrm{~nm}$. XPS measurements were conducted using an $\mathrm{Al}$ $\mathrm{X}$-ray monochromatic source $(1486.6 \mathrm{eV})$. The elemental composition was calculated from the high-resolution (HR) spectra acquired with the following parameters: a pass energy of $40 \mathrm{eV}$, a step width of $0.2 \mathrm{eV}$ and a dwell time of $200 \mathrm{~ms}$. The etching was realised with an Argon beam of $5 \mathrm{keV}$ and the etch spot diameter was about $500 \mu \mathrm{m}$. For both methods, the fibres were glued on an Indium plate which was taped on a metallic support.

Table 1. XPS fitting parameters of the $\mathrm{O}^{17-18}, \mathrm{C}^{19-21}$ and $\mathrm{Si}^{22-23} \mathrm{HR}$ spectra.

\begin{tabular}{|l|l|l|}
\hline Chemical functions & $\begin{array}{l}\text { Binding energy } \\
(\mathrm{eV})\end{array}$ & $\begin{array}{l}\text { Full width at half } \\
\text { maximum }(\mathrm{eV})\end{array}$ \\
\hline$(\mathrm{Si} 2 \mathrm{p}) \mathrm{Si}-\mathrm{C}$ & $99.5-100.5$ & $0.9-1.1$ \\
\hline$(\mathrm{Si} 2 \mathrm{p}) \mathrm{Si}-\mathrm{O}-\mathrm{C}$ & $\mathrm{SiC}+1.0$ & $0.9-1.1$ \\
\hline$(\mathrm{Si} 2 \mathrm{p}) \mathrm{Si}-\mathrm{O}_{2}-\mathrm{C}_{2}$ & $\mathrm{Si}-\mathrm{O}-\mathrm{C}+1.0$ & $1.0-1.2$ \\
\hline$(\mathrm{Si} 2 \mathrm{p}) \mathrm{SiO}_{4}$ & $103.0-103.5$ & $1.0-1.3$ \\
\hline$(\mathrm{C} 1 \mathrm{~s}) \mathrm{C}-\mathrm{Si}$ & $282.5-282.7$ & $0.9-1.1$ \\
\hline$(\mathrm{C} 1 \mathrm{~s}) \mathrm{C}-\mathrm{O}-\mathrm{Si}$ & $\mathrm{C}-\mathrm{Si}+1.0$ & $0.9-1.1$ \\
\hline
\end{tabular}




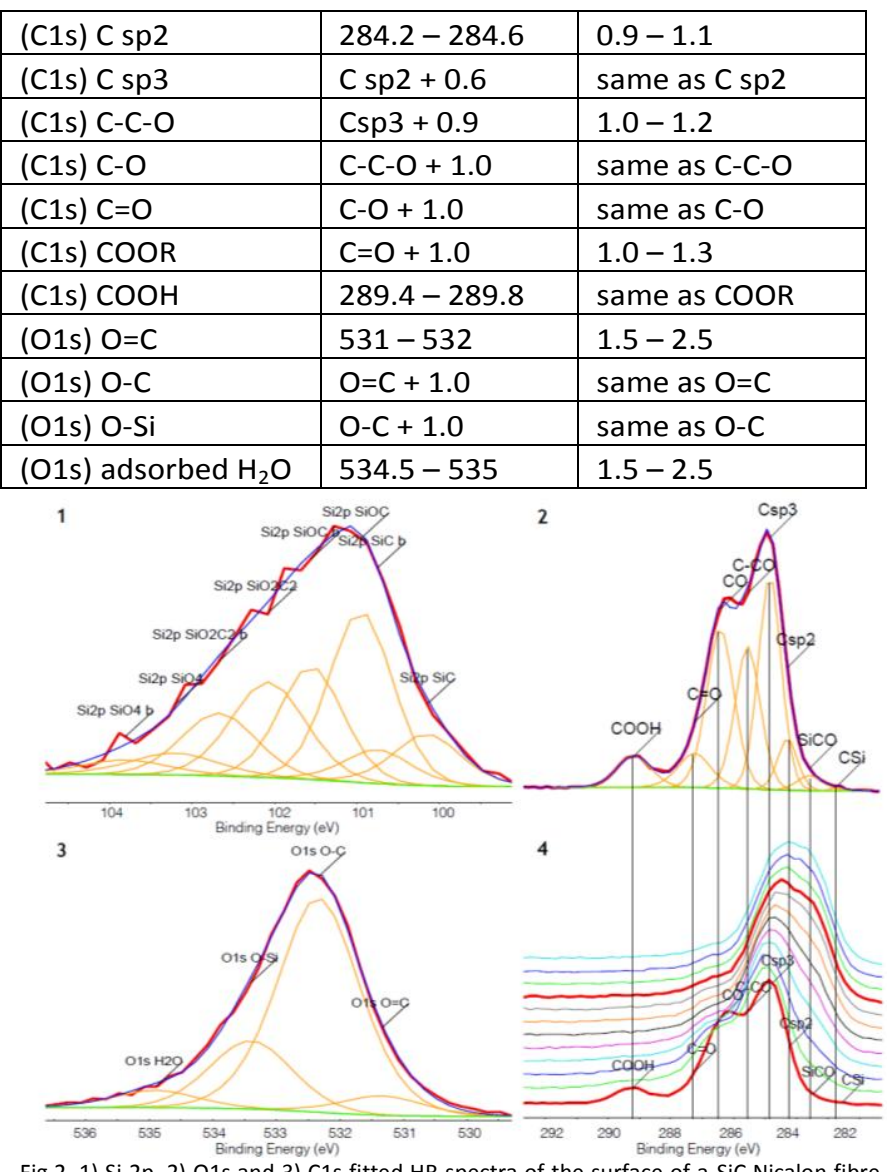

Fig.2. 1) Si 2p, 2) O1s and 3) C1s fitted HR spectra of the surface of a SiC Nicalon fibre. 4) Etching profile of $\mathrm{C} 1 \mathrm{~s}$ spectrum.

Characteristic peaks of oxygen (O), nitrogen (N), carbon (C) and silicon (Si) atoms were recorded at 533, 402, 285 and 101 $\mathrm{eV}$, respectively and at each etch level. Peak areas were converted into atomic concentration through the sensitivity factors ${ }^{23,24}$ with an uncertainty of 5 to $10 \%$. HR spectra of C1s were fitted using a 30 to $50 \%$ ratio of a Lorentzian and Gaussian function type lines and a Shirley type background. ${ }^{25}$ Using Table 1, fitted HR spectra are obtained and shown in Fig.2. On the Si2p spectrum, for each $p$ orbital, a doublet is considered $\left(p_{1 / 2}\right.$ and $\left.p_{3 / 2}\right)$ due to spin-orbit coupling. The height of the $p_{1 / 2}$ orbital is equal to 0.56 times the $p_{3 / 2}$ orbital. The gap between the two orbitals is fixed at $0.6 \mathrm{eV}$.

For the microstructural characterisation, $\mathrm{Au}$ nanoparticles were deposited on the filament surface of the treated tow. Then, a sandwich material was built with a Si wafer, at the bottom, and a glass plate, at the top. And a composite, which corresponds to the treated fibres embedded in a cured epoxy resin, was placed in between. Thin slices of the sandwich material were cut and polished before being subjected to ionic beam thinning (Cryo lon Slicer EM 09100IS from JEOL). The $C$ film was observed by Transmission Electron Microscopy (TEM $6700 \mathrm{~F}$ from JEOL at $200 \mathrm{keV}$ ) and the O, C and Si atom distribution was revealed by Scanning Transmission Electron Microscopy (STEM).

Finally, elemental analyses were intended to quantify Si atoms released in the reactive medium after treatment by ICP-OES (720ES from Varian).

\section{Results and discussion}

\subsection{C film formation in water under pressure and temperature}

In a hydrothermal medium, SiC materials are subjected to corrosion. Above $500{ }^{\circ} \mathrm{C}$ and $100 \mathrm{MPa}$, crystalline phases of the Nicalon fibre interact with water if the molar ratio of $\mathrm{H}_{2} \mathrm{O}: \mathrm{SiC}$ is above $2: 1$ according to the following equation ${ }^{26}$ :

$$
\mathrm{SiC}(\mathrm{s})+2 \mathrm{H}_{2} \mathrm{O} \rightarrow \mathrm{SiO}_{2}(\mathrm{~s})+\mathrm{CH}_{4}(\mathrm{~g})
$$



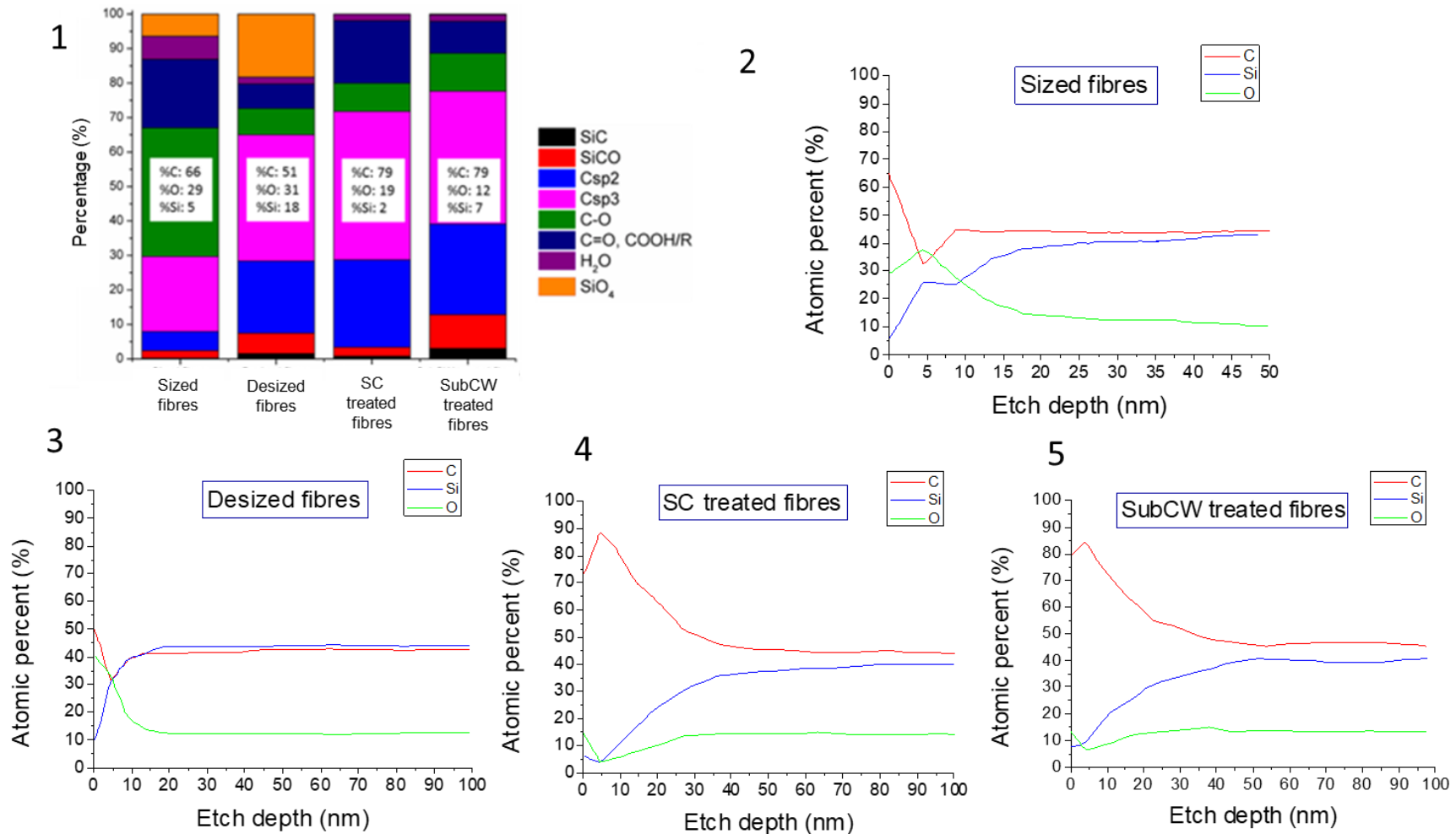

Fig. 3 1) Schematic representation of the chemical functionalities of the surface of sized, desized, SC (Safran Ceramics) treated and SubCW treated fibres. AES depth profiles of 2) sized, 3) desized, 4) SC treated and 4) SubWC treated fibres.

If the molar ratio of $\mathrm{H}_{2} \mathrm{O}: \mathrm{SiC}$ is exactly $2: 1$, then solid $\mathrm{C}$ is produced as follow ${ }^{27-29}$ :

$$
\mathrm{SiC}(\mathrm{s})+2 \mathrm{H}_{2} \mathrm{O} \rightarrow \mathrm{SiO}_{2}(\mathrm{~s})+\mathrm{C}(\mathrm{s})+2 \mathrm{H}_{2}(\mathrm{~g})
$$

Similarly, the dissolution of the amorphous phase starts around $300-400{ }^{\circ} \mathrm{C}$ and $100 \mathrm{MPa}^{29-30}$ :

$$
\mathrm{SiC}_{x} \mathrm{O}_{y}(\mathrm{~s})+(2-\mathrm{y}) \mathrm{H}_{2} \mathrm{O} \rightarrow \mathrm{SiO}_{2}(\mathrm{~s})+\mathrm{xC}(\mathrm{s})+(2-\mathrm{y}) \mathrm{H}_{2}(\mathrm{~g})
$$

Hence, a C film grows on the SiC surface from $10 \mathrm{~nm}$ up to 1 $\mu \mathrm{m}$ depending on the treatment time and temperature. As the pressure and temperature ranges of our study are lower than these previous studies, silica was not identified at the surface of our treated fibres. From Fig.3, the treatment, performed below $400{ }^{\circ} \mathrm{C}$ and at a pressure comprised between the saturated pressure and $30 \mathrm{MPa}$, proved the feasibility of obtaining fibres with similar surface properties than the fibres treated with the reference acid-based treatment. The subCW treated fibres were coated with a C film with a thickness of 29 $\mathrm{nm}$ and the O-rich layer was removed. From literature, it was reported the possibility to form hydrosoluble silica instead of the solid silica after corrosion of $\mathrm{SiC}$ in heated water $\left(290^{\circ} \mathrm{C}\right)$. Hirayama et al. proposed the formation of silicic acid ${ }^{31}$ :

$$
\mathrm{SiC}(\mathrm{s})+4 \mathrm{H}_{2} \mathrm{O}(\mathrm{g}) \rightarrow \mathrm{Si}(\mathrm{OH})_{4}(\mathrm{aq})+\mathrm{CH}_{4}(\mathrm{~g})
$$

This soluble silica is not able to agglomerate and to densify at the fibre surface. Accordingly, it is believed that soluble silica is also produced during our treatment. However, TEM investigation highlighted the formation of a C-rich layer of about $100 \mathrm{~nm}$ (Fig. 4). Hence, it is suggested that the O-rich layer formed at the fibre surface was attacked under subcritical conditions to give rise to a C-rich layer as the following:

$$
\mathrm{SiC}(\mathrm{s})+4 \mathrm{H}_{2} \mathrm{O}(\mathrm{aq}) \rightarrow \mathrm{Si}(\mathrm{OH})_{4}(\mathrm{aq})+\mathrm{C}(\mathrm{s})+2 \mathrm{H}_{2}(\mathrm{~g})
$$

$$
\mathrm{SiC}_{x} \mathrm{O}_{y}(\mathrm{~s})+(4-\mathrm{y}) \mathrm{H}_{2} \mathrm{O}(\mathrm{aq}) \rightarrow \mathrm{Si}(\mathrm{OH})_{4}(\mathrm{aq})+\mathrm{xC}(\mathrm{s})+2(2-\mathrm{y}) \mathrm{H}_{2}(\mathrm{~g})
$$

Indeed, subcritical water exhibits specific properties. For example, its ionic product $(\mathrm{Ke})$ reaches its maximum between 100 and $350{ }^{\circ} \mathrm{C}$ whereas it falls dramatically above the critical temperature (Fig. 5). ${ }^{32}$ This means that subcritical water has a high concentration of charged species in comparison with 
supercritical water (if the pressure stays below $100 \mathrm{MPa}$ ). ${ }^{33}$ At the opposite, supercritical water completely solubilises oxygen and organics. ${ }^{34}$ That is why hydrolysis reactions are favoured in the subcritical region of water compared to oxidations reactions that dominate in the supercritical domain. Moreover, some studies pointed out high dissolution rate of Si-based materials ( $\mathrm{Si}$ single crystal, amorphous silica and $\mathrm{SiOC}$ ceramics) in subcritical water. ${ }^{35-42}$ In opposite to Gogotsi et al. and Yoshimura et al., the subcritical treatment of this study engenders hydrolysis reactions to form a C coating by dissolution of an O-rich layer at the fibre surface. Hence, our temperature and pressure ranges are much lower and the treatment time is largely decreased by operating in a semicontinuous mode. The next section will focus on the understanding of the Si extraction mechanism by modifying the physico-chemical properties of the reactive medium.
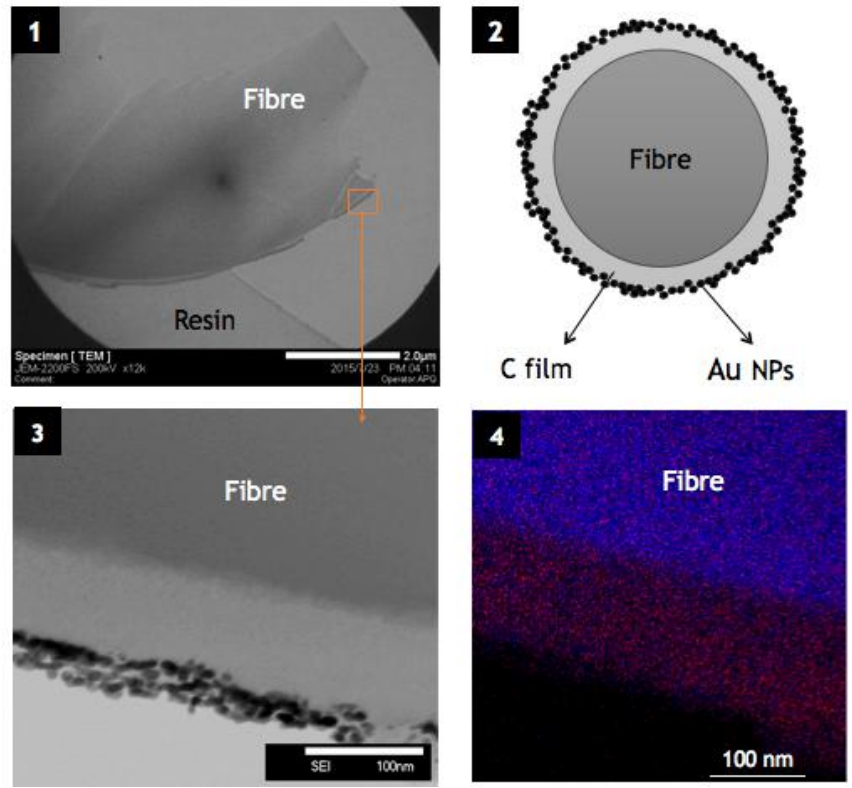

Fig. 4 TEM micrographs of a 1), 3) cross section of a treated fibre with 2) a schematic representation and 4) a STEM analysis of Si (blue) and C (red) atoms. NPs: nanoparticles.

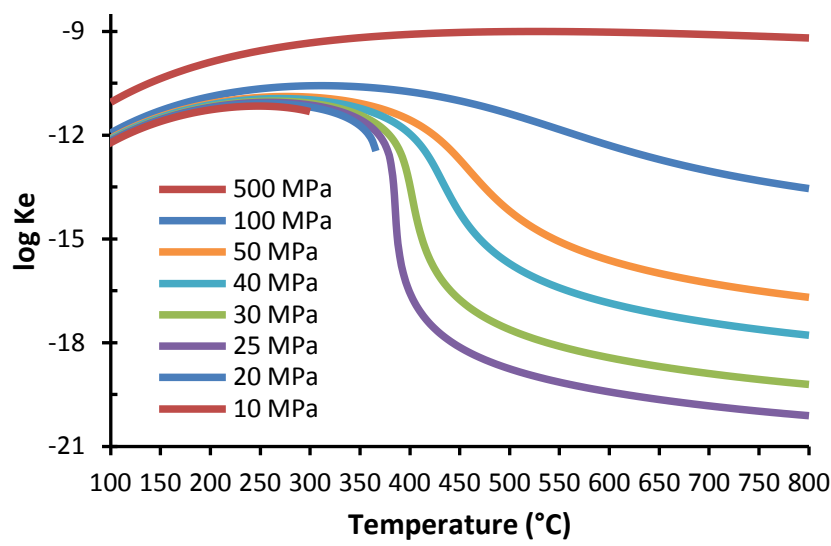

Fig. 5 Evolution of the lonic Product (Ke) of water regarding temperature (from 100 to $800{ }^{\circ} \mathrm{C}$ ) and pressure (from 10 to $500 \mathrm{MPa}$ ). The graph was plotted according to the equation developed by Bandura et al. ${ }^{32}$

\subsection{Mechanism and kinetics of the treatment}

Firstly, Allongue et al. identified the etching mechanism of a Sisingle crystal in alkaline solution under ambient temperature and pressure. ${ }^{43}$ The $\mathrm{Si}$ atoms at kink sites were directly attacked by water until it forms silicic acid, a soluble molecule. As subcritical water displays a high concentration of $\mathrm{HO}^{-}$and $\mathrm{H}_{3} \mathrm{O}^{+}$ions, it could be possible for the $\mathrm{Si}$ atoms of the Nicalon fibres to undergo several nucleophilic attacks. In order to verify their fundamental role in the fibre treatment mechanism, ethanol was used as a reactive medium. Although ethanol can be involved into solvolysis reactions, it does not have the capacity to generate ions (pKa $=16) .{ }^{44}$ Besides, as it demonstrates a lower dielectric constant ${ }^{45}$ than water, the dissolution rate of $\mathrm{Si}$ atoms is expected to decrease while increasing its proportion into the reactive medium. Several experiments were performed at temperatures below $400{ }^{\circ} \mathrm{C}$ and at a pressure comprised between the saturated pressure and $30 \mathrm{MPa}$ but at different volume fractions of ethanol. From Fig. 6.1 it appears that the chemical functionalities of the treated fibres are similar, except for the one treated in a pure ethanol medium.

All the fibre surfaces demonstrate a high $\mathrm{C}$ content and a low $O$ content which reveals a high efficiency of the treatment. However, the use of pure ethanol only permits to remove the sizing agent from fibres. This explains the high content of oxide $\left(\mathrm{SiO}_{4}\right)$ and the low $\mathrm{C}$ content at their surface. From Fig. 6.2, it is noticed that the quantity of dissolved $\mathrm{Si}$ atoms drops, i.e. the kinetics slow down, when the ethanol proportion increases in the reactive medium. As the addition of ethanol resulted in the decrease of ions concentration, it can be said that the presence of ions in subcritical water enables the hydrolysis reactions to occur. To conclude, the mechanism of our treatment allowed the study of the kinetics. Regarding the understood reactions (1.5) and (1.6), either the concentration of silicic acid or the $\mathrm{C}$ film thickness can be followed to assess the kinetics of the hydrothermal treatment.

As the process is semi-continuous, the flowrate parameter needs to be incorporated into the kinetics calculations.

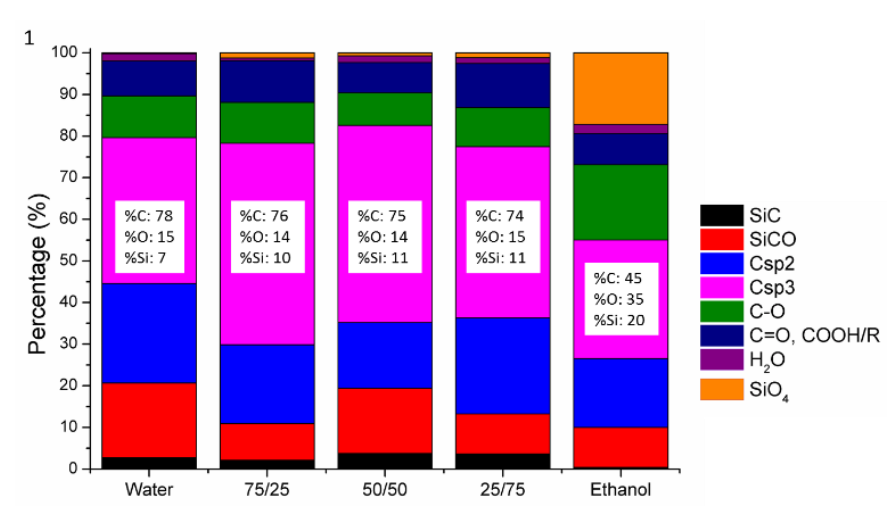


2

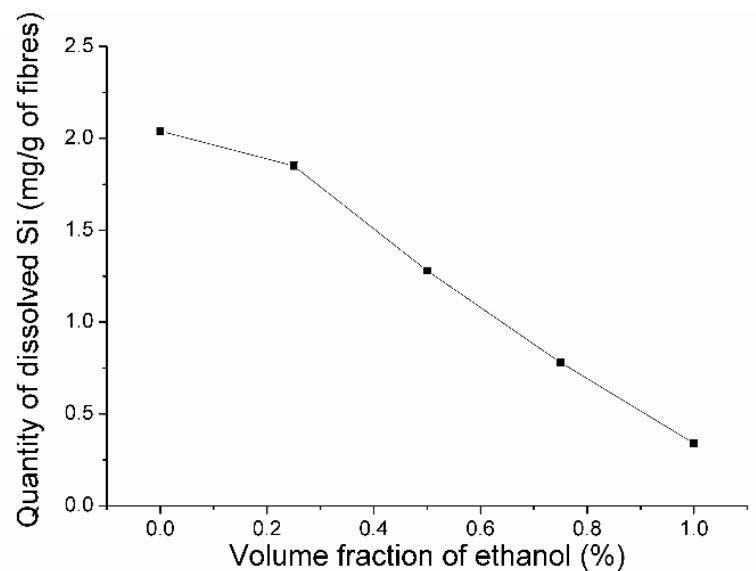

Fig. 6 1) schematic representation of the chemical tunctionalities of the surtace of the treated fibres regarding the nature of the reactive medium. 2) Evolution of the quantity of dissolved $\mathrm{Si}$ as a function of the volume fraction of ethanol.

For that reason, a water quantity was calculated for each experiment by multiplying the flowrate by the treatment time. This approximation can be reasonably done over our range of study because, according to Fig. 7, the quantity of dissolved Si linearly evolves with the flowrate. Hence, this parameter can be plotted versus the quantity of water. From Fig. 8, linear fits were obtained for the evolution of the $\mathrm{Si}$ concentration at different temperatures $\left(250,300,315,350{ }^{\circ} \mathrm{C}\right)$ and at a pressure comprised between the saturated pressure and 30 $\mathrm{MPa}$. As the silicic acid released from equation (1.5) cannot be discriminated from the one released from equation (1.6), the results will indicate a global kinetic for the formation of the silicic acid species. Similarly, an initial quantity of $\mathrm{Si}$ was referred as the sum of the $\mathrm{Si}$ atoms included in the crystalline and amorphous phases of the fibres [ $\left.\mathrm{Si}_{\mathrm{tot}}\right]$.

The differential rate equation is:

$$
\frac{d\left[\mathrm{Si}^{\left.(\mathrm{OH})_{4}\right]}\right.}{d t}=k\left[\mathrm{Si}_{\text {tot }}\right]^{\alpha}\left[\mathrm{H}_{2} \mathrm{O}\right]^{\beta}
$$

with $k$ the rate constant, $\alpha$ and $\beta$, the reaction orders regarding $\left[\mathrm{Si}_{\text {tot }}\right]$ and $\left[\mathrm{H}_{2} \mathrm{O}\right]$, respectively. According to the literature, the corrosion kinetics of $\mathrm{SiC}$ in a hydrothermal medium are limited by the reactions at the interface. ${ }^{46}$ In this study, it is obvious that the chemical reactions occur on a $2 \mathrm{D}$ surface which always regenerates.

In fact, one can imagine that the reactants are consumed layer by layer and that a new interface appears constantly. So, in the studied system, the $\left[\mathrm{Si}_{\text {tot }}\right]$ quantity is considered as infinite. The same argument is applied to the $\left[\mathrm{H}_{2} \mathrm{O}\right]$ quantity as water is in large excess in our system. In fact, water is both the reactant and the solvent, and it is continuously renewed due to the semi-continuous mode. The $\left[\mathrm{Si}_{\text {tot }}\right]$ and $\left[\mathrm{H}_{2} \mathrm{O}\right]$ quantities do not vary significantly during the treatment and are therefore considered equal to 1 .

Then, the equation is:

$$
\frac{d\left[\mathrm{Si}(\mathrm{OH})_{4}\right]}{d t}=\mathrm{k}
$$

$$
\left[\mathrm{Si}(\mathrm{OH})_{4}\right]=\mathrm{kt}
$$

$\mathrm{t}$, the time, will be replaced by the water quantity $(\mathrm{mg} / \mathrm{g}$ of fibres/g).

From Fig. 8, the evolution of dissolved $\mathrm{Si}$ for different temperatures along with the water quantity follows a linear regime. Hence, the Arrhenius empiric law could be used from the following equation:

$$
k=A e^{-\left(\frac{E_{A}}{R T}\right)}
$$

$A$ is the pre-exponential factor, $E_{A}$, the global activation energy, $\mathrm{R}$, the perfect gas factor and $\mathrm{T}$, the temperature. By plotting Ink versus $1 / T$ (data in Table 2 ), it is possible to determine $A$ and $E_{A}$. As a linear fit was obtained $\left(R^{2}=0.99\right)$, the $E_{A}$ value was calculated to be $56 \mathrm{~kJ} / \mathrm{mol}$. This value is 3 times less than the one for the $\mathrm{SiC}$ corrosion following the reactions (1.2) and (1.3) that occurred between 500 and $800{ }^{\circ} \mathrm{C}$ under $200 \mathrm{MPa}^{47}$

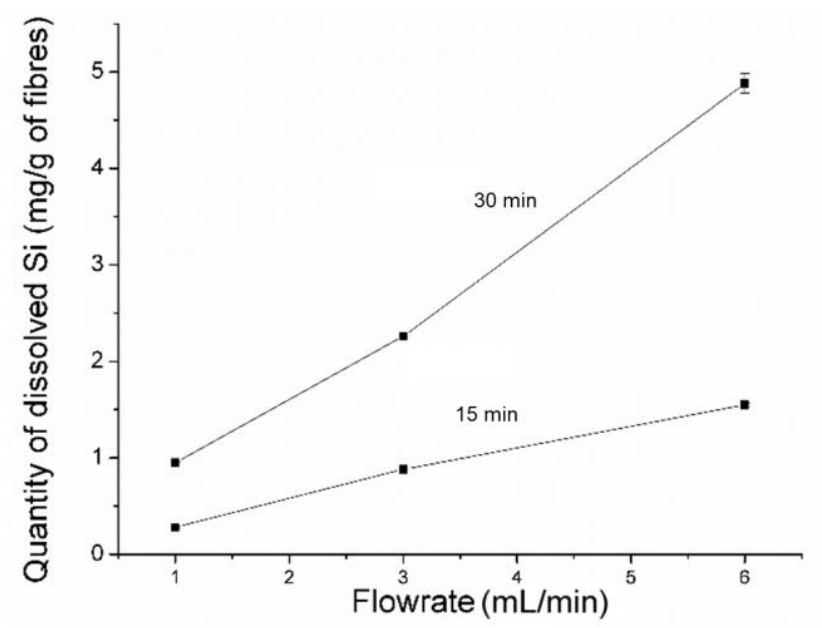

Fig. 7 Evolution of the quantity of dissolved $\mathrm{Si}$ in the medium as a function of the flowrate. The fibres were water treated with the same temperature and pressure conditions than for Fig. 3.

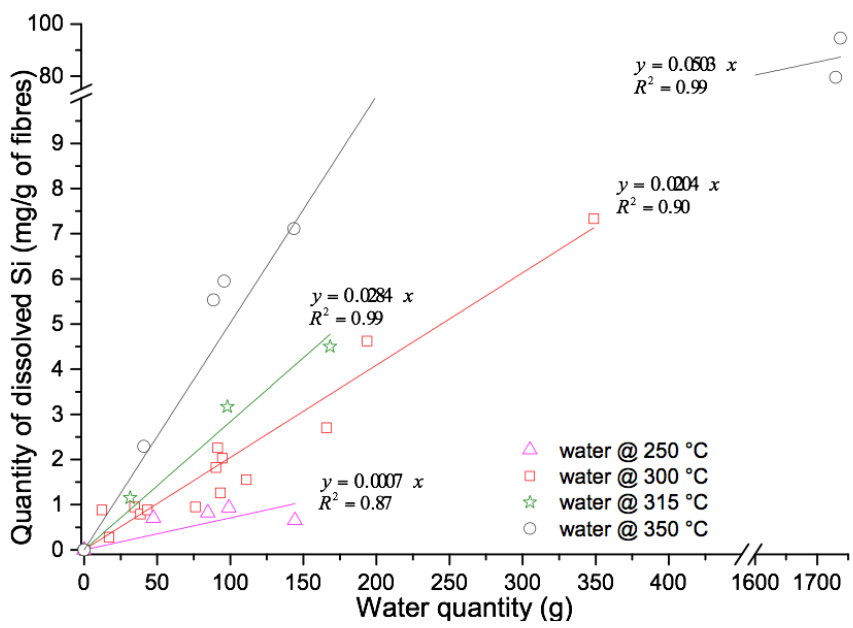

Fig. 8: Evolution of the quantity of dissolved $\mathrm{Si}$ in the water medium as a function of the quantity of used water.

The solution is: 
This points out that different mechanisms are involved in the corrosion of SiC-based materials depending on the temperature and pressure ranges of water. Indeed, as oxidation kinetics are low between 200 and $350{ }^{\circ} \mathrm{C},{ }^{47}$ hydrolysis reactions dominate in subcritical water. In addition, it is worth to mention the crystallinity difference between $\mathrm{SiC}$ particles and the Nicalon fibres, which contain a large amount of amorphous phase. For example, the calculated $\mathrm{E}_{\mathrm{A}}$ value is close to the $E_{A}$ dissolution value of amorphous silica between 25 and $100{ }^{\circ} \mathrm{C}$ at neutral $\mathrm{pH}(55 \mathrm{~kJ} / \mathrm{mol})^{48}$ and in supercritical water between 400 and $600{ }^{\circ} \mathrm{C}$ at $60 \mathrm{MPa}(60 \mathrm{~kJ} / \mathrm{mol}) .{ }^{49}$ Again, the global activation energy of Nicalon dissolution into subcritical water is comprised in the $28-80 \mathrm{~kJ} / \mathrm{mol}$ range corresponding to the corrosion of oxycarbidic silicon phases between 150 and $250{ }^{\circ} \mathrm{C}$ and 0.5 to $4 \mathrm{MPa} .{ }^{39}$ The large range of values is linked to the measurement of Si concentration in a closed system that tends to be saturated after a long treatment time.

To conclude, the study revealed a zero-order kinetics for the surface treatment developed in this paper. The treatment takes place at a constant rate completely independent of the reactant concentration.

Table 2 Slope (equivalent to $\mathrm{k}$ ) and $\mathrm{R}^{2}$ values extracted from the linear fit on Fig. 8 and input data for the Arrhenius plot.

\begin{tabular}{|l|l|l|l|l|}
\hline $\begin{array}{l}\text { Temperature } \\
\left({ }^{\circ} \mathrm{C}\right)\end{array}$ & $\begin{array}{l}\text { Slope }(\mathrm{mg} / \mathrm{g} \\
\text { de fibres/g) }\end{array}$ & $\mathrm{R}^{2}$ & $1 / \mathrm{T}\left(\mathrm{K}^{-1}\right)$ & $\operatorname{ln~} \mathrm{k}$ \\
\hline 250 & 0.0007 & 0.87 & 0.00191 & -4.96 \\
\hline 300 & 0.0204 & 0.90 & 0.00174 & -3.89 \\
\hline 315 & 0.0284 & 0.99 & 0.00170 & -3.56 \\
\hline 350 & 0.0503 & 0.99 & 0.00161 & -2.99 \\
\hline
\end{tabular}

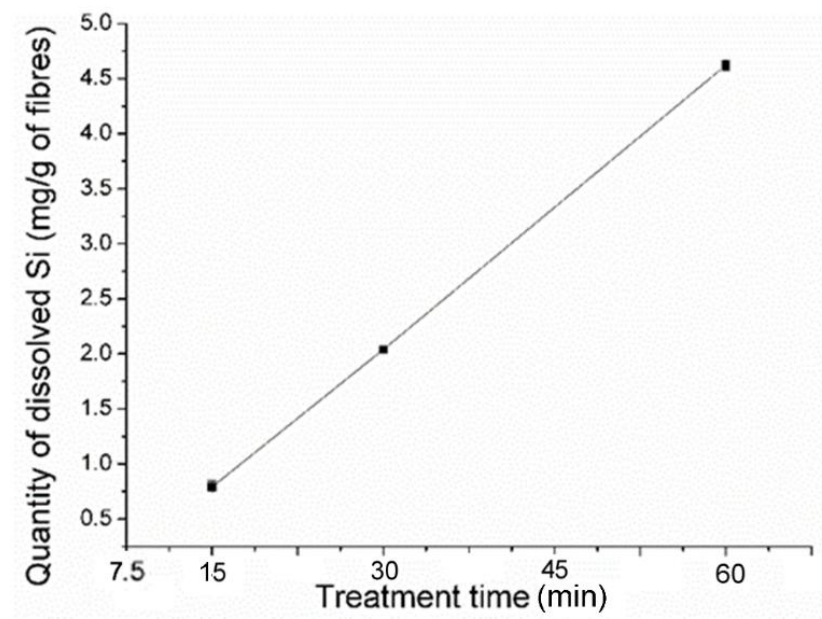

Fig. 9 Evolution of the quantity of dissolved $\mathrm{Si}$ as a function of the treatment time.

The semi-continuous process allowed running the treatment in specific conditions where the excess of water resulted in highly catalysed reactions without any saturation effect of the produced silica. As it is figured on the graphs (Fig. 7 and Fig. 9), the $\mathrm{Si}$ atoms etching can be precisely controlled during the hydrothermal treatment. Indeed, the flowrate and the treatment time parameters are easily accessible to tune the $\mathrm{Si}$ atoms etching and, consequently, the thickness of the $\mathrm{C}$ film which is the primordial key to optimise the mechanical properties of CMCs.

\section{Conclusions}

According to this study, a green and innovative semicontinuous treatment was successfully adapted to the surface functionalisation of ceramic materials. Besides, we can affirm that the hydrothermal treatment of the Nicalon fibre under subcritical conditions occurs via $\mathrm{Si}$ atoms hydrolysis of the crystalline and amorphous phases. The reactions lead to the production of silicic acid in the medium and the generation of a $\mathrm{C}$ film at the outer of the filaments. The strong potential of the process resulted from several factors: i) the acid-base properties of water in the studied ranges of pressure and temperature, as a high ions concentration catalyses the $\mathrm{Si}$ atoms hydrolysis, ii) the polarity and proticity of the reactive medium which helps both the hydroxylated surface of the fibres to get involved into strong interaction with water and the stabilisation and solvatation of the silicic acid, iii) the temperature and pressure ranges of water which lead to enhanced silica solubility, and iv) the semi-continuous operating mode that regenerates the reactive medium and establishes a constant rate process. Hence, the hydrolysis reactions do not seem to be limited by water diffusion through the $C$ film but by the reactions that take place at the fibre/C interface.

To conclude, the replacement of the acidic treatment by this new method will participate to the expansion of green solutions applied to the elaboration process of ceramic-based materials.

\section{Conflicts of interest}

There are no conflicts of interest to declare.

\section{Acknowledgements}

The authors would like to thank the Direction Générale de I'Armement (DGA), the Région Nouvelle Aquitaine and Safran Ceramics company for their financial support. The authors would like to thank Christine Labrugère and Michel Lahaye for their support to surface analyses.

\section{References}

1 International Air Transport Association (IATA), Annual Review 2019 released for IATA's General Meeting, 2019.

2 W. Krenkel, Carbon fibre reinforced silicon carbide composites (C/SiC, C/C-SiC) in Handbook of ceramic composites, 2005, Springer.

3 Ceramics.org (American Ceramic Society website).

4 G. S. Corman and K. L. Luthra, Silicon melt infiltrated ceramic composites (hipercomp) in Handbook of ceramic composites, 2005, Springer.

5 J. A. DiCarlo, H. -M. Yun, G. Morscher and R. T. Bhatt, SiC/SiC composites for $1200{ }^{\circ} \mathrm{C}$ and above in Handbook of ceramic composites, 2005, Springer.

6 G. Roewer, H. Herzog, K. Trommer, E. Müller and S. Frühauf, Silicon carbide - A survey of synthetic approaches, properties and applications, in High performance non-oxide ceramics I (Vol. 12), 2002, Springer. 
7 C. Laffon, A. M. Flank, P. Lagarde, M. Laridjani, R. Hagege, P. Olry, J. Cotteret, J. Dimier, J. L. Miquel and H. Hommel, Journal of Materials Science, 1989, 24(4), 1503-1512.

8 Y. Maniette and A. Oberlin, Journal of Materials Science, 1989, 24(9), 3361-3370.

9 Ph. Schreck, C. Vix-Guterl and J. Lahaye, Journal of Materials Science, 1992, 27(15), 4243-4246.

10 J. G. Thebault, FR Patent, 1984, 2.567.874.

11 J. Lamon, Chemical Vapor Infiltrated SiC/SiC composites (CVI $\mathrm{SiC} / \mathrm{SiC}$ ) in Handbook of ceramic composites, 2005, Springer.

12 D. Marshall and B. Cox, Encyclopaedia of Aerospace Engineering, Chap. Textile Composite Materials: Ceramic Matrix Composites, 2010, John Wiley \& Sons.

13 S. Loison, FR Patent, 2013, W02013153336 A1.

14 J. Reglero, FR Patent, 2014, WO2014114874 A1.

15 B. Basalavingu, K. Byrappa, M .Yoshimura, P. Mashusudan, A. S. Dayananda, Journal of materials science, 41 (2006) 1465-1469.

16 L. Z. Pei, Y. H. Tang, Y. W. Chen, C. Guo, X. X. Li, Y. Yuan, and Y. Zhang, Journal of Applied Physics, 99, 114306 (2006).

17 O. Akhavan, Carbon, 2010, 48(2), 509-519.

18 C. Hontoria-Lucas, A. J. Lopez-Peinado, J. D. de LópezGonzález, M. L. Rojas-Cervantes and R. M. Martin-Aranda, Carbon, 1995, 33(11), 1585-1592.

19 A. Ganguly, S. Sharma, P. Papakonstantinou and J. Hamilton, Journal of Physics Chemistry C, 2011, 115(34), 17000-17019.

20 C. Mattevi, G. Eda, S. Agnoli, S. Miller, K. A. Mkhoyan, O. Celik, D. Mastrogiovanni, G. Granozzi, E. Garfunkel and M. Chhowalla, Advanced Functional Materials, 2009, 19(16), 2577-2583.

21 D. Yang, A. Velamakanni, G. Bozoklu, S. Park, M. Stoller, R. D. Piner, S. Stankovich, I. Jung, D. A. Field, C. A. Ventrice, Jr., and R. S. Ruoff, Carbon, 2009, 47(1), 145-152.

22 G. D. Sorarù, G. D'Andrea and A. Glisenti, Materials Letters, 1996, 27(1), 1-5.

23 M. P. Seah and I. S. Gilmore, Surface and Interface Analysis, 1998, 26(12), 908-929.

24 M. P. Seah, I. S. Gilmore and S. J. Spencer, Journal of Electron Spectroscopy and Related Phenomena, 2001, 120(1), 93-111.

25 D. A. Shirley, Physical Review B, 1972, 5(12), 4709-4714.

26 M. Yoshimura, J. Kase and S. Somiya, Journal of Material Research, 1986, 1(1), 100-103.

27 Y. Gogotsi and M. Yoshimura, Nature, 1994, 367, 628-630.

28 N. S. Jacobson, Y. Gogotsi and M. Yoshimura, Journal of Materials Chemistry, 1995, 5(14), 595-601.

29 Y. Gogotsi, M. Yoshimura, M. Kakihana, Y. Kanno and M. Shibuya, Ceramic Processing Science and Technology, Ceramic Transactions, 1995, 51, 243-247.

30 Y. Gogotsi and M. Yoshimura, Journal of Materials Science Letters, 1995, 14(10), pp. 755-759.

$31 \mathrm{H}$. Hirayama, T. Kawakubo and A. Goto, Journal of the American Ceramic Society, 1989, 72(11), 2049-2053.

32 A. V. Bandura and S. N. Lvov, Journal of Physical and Chemical Reference Data, 2006, 35(1), 15-30.

33 P. Kritzer, N. Boukis and E. Dinjus, The Journal of Supercritical Fluids, 1999, 15(3), 205-227.

34 M. Modell, US Patent, 1982, 4.338.199.

35 R. O. Fournier and J. J. Rowe, American Mineralogist, 1977, 62(9-10), 1052-1056.

36 T. Futatsuki, T. Oe, H. Aoki, N. Komatsu, C. Kimura and T. Sugino, Japanese Journal of Applied Physics, 2010, 49(4S) 04DF18.

37 T. Futatsuki, T. Oe, H. Aoki, N. Komatsu, C. Kimura and T. Sugino, Applied Surface Science, 2010, 256(22), 6512-6517.

38 R. K. Iler, The chemistry of silica: Solubility, polymerization, colloid and surface properties, and biochemistry, 1979, New York: Wiley.
39 N. Ingri, Proceedings of the $40^{\text {th }}$ Nobel Symposium held in Lindingo, Sweden, 1977, 40.

40 P. Karásek, L. St'avíková, J. Planeta, B. Hohnová and M. Roth, The Journal of Supercritical Fluids, 2013, 83, 72-77.

41 C. Linck, E. Ionescu, B. Papendorf, D. Galuskova, D. Galusek, P. Ŝajgalík, and R. Riedel, International Journal of Materials Research, 2012, 103(1), 31-39.

42 A. Yoko and Y. Oshima, The Journal of Supercritical Fluids, 2013, 75, 1-5.

$43 \mathrm{P}$. Allongue, H. Brune and H. Gerischer, Surface Science, 1992, 275(3), 414-423.

44 E. -I. Negishi and A. de Meijere, Handbook of organopalladium chemistry for organic synthesis (Vol. 1), 2002, New York: Wiley-Interscience.

45 D. P. Fernández, Y. Mulev, A. R. H. Goodwin and J. M. H. Levelt Sengers, Journal of Physical and Chemical Reference Data, 1995, 24(1), 33-70.

46 K. A. Terrani, Y. Yang, Y. -J. Kim, R. Rebak, H. M. Meyer III and T. J. Gerczak, Journal of Nuclear Materials, 2015, 465, 488-498.

47 T. Kraft, K. G. Nickel and Y. Gogotsi, Journal of Materials Science, 1998, 33(17), 4357-4364.

48 B. A. Fleming, Journal of Colloid and Interface Science, 1986, 110(1), 40-64.

49 N. Yanagisawa, K. Fujimoto, S. Nakashima, Y. Kurata and N. Sanada, Geochimica Et Cosmochimica Acta, 1997, 61(6), $1165-1170$ 